\title{
Muscadine grape skin extract reverts snail-mediated epithelial mesenchymal transition via superoxide species in human prostate cancer cells
}

Liza J Burton ${ }^{1 \dagger}$, Petrina Barnett ${ }^{1 \dagger}$, Basil Smith ${ }^{1}$, Rebecca S Arnold ${ }^{2}$, Tamaro Hudson ${ }^{3}$, Kousik Kundu ${ }^{4}$, Niren Murthy ${ }^{4}$ and Valerie A Odero-Marah ${ }^{1 *}$

\begin{abstract}
Background: Snail transcription factor can induce epithelial-mesenchymal transition (EMT), associated with decreased cell adhesion-associated molecules like E-cadherin, increased mesenchymal markers like vimentin, leading to increased motility, invasion and metastasis. Muscadine grape skin extract (MSKE) has been shown to inhibit prostate cancer cell growth and induce apoptosis without affecting normal prostate epithelial cells. We investigated novel molecular mechanisms by which Snail promotes EMT in prostate cancer cells via Reactive Oxygen Species (ROS) and whether it can be antagonized by MSKE.

Methods: ARCaP and LNCaP cells overexpressing Snail were utilized to examine levels of reactive oxygen species (ROS), specifically, superoxide, in vitro using Dihydroethidium (DHE) or HydroCy3 dyes. Mitosox staining was performed to determine whether the source of ROS was mitochondrial in origin. We also investigated the effect of Muscadine grape skin extract (MSKE) on EMT marker expression by western blot analysis. Migration and cell viability using MTS proliferation assay was performed following MSKE treatments.

Results: Snail overexpression in ARCaP and LNCaP cells was associated with increased concentration of mitochondrial superoxide, in vitro. Interestingly, MSKE decreased superoxide levels in ARCaP and LNCaP cells. Additionally, MSKE and Superoxide Dismutase (SOD) reverted EMT as evidenced by decreased vimentin levels and re-induction of E-cadherin expression in ARCaP-Snail cells after 3 days, concomitant with reduced cell migration. MSKE also decreased Stat-3 activity in ARCaP-Snail cells.

Conclusions: This study shows that superoxide species may play a role in Snail transcription factor-mediated EMT. Therefore, therapeutic targeting of Snail with various antioxidants such as MSKE may prove beneficial in abrogating EMT and ROS-mediated tumor progression in human prostate cancer.
\end{abstract}

Keywords: Muscadine grape skin extract, Snail, EMT, Reactive oxygen species, Superoxide, Prostate cancer

\footnotetext{
*Correspondence: vodero_marah@cau.edu

${ }^{\dagger}$ Equal contributors

${ }^{1}$ Center for Cancer Research and Therapeutic Development, Department of Biological Sciences, Clark Atlanta University, 223 James P Brawley Dr SW, 30314 Atlanta, GA, USA

Full list of author information is available at the end of the article
} 


\section{Background}

The muscadine grape possesses one of the highest antioxidant levels among fruits; yet, the effect of this fruit on mammalian metabolic systems has not received significant attention [1]. Muscadine Grape Skin Extract (MSKE) derived from the muscadine grape (Vitis rotundifolia) differs from the more common red grapes used to produce red wines, which normally contain resveratrol. Based on the skin color, muscadine varieties are referred respectively as bronze and purple compared to white and red for all other grapes [2]. Muscadine grapes are native to Southeastern United States and can be found growing wild from Delaware to the Gulf of Mexico and westward from Missouri to Texas [3]. In a study done by Hudson et al., it was determined that the major phytochemical constitute of MSKE is anthocyanin 3,5-diglucosides which is different from resveratrol [4]. The phenolic structure of anthocyanins is responsible for their antioxidant activity (ability to scavenge ROS) [5]. Reactive Oxygen Species (ROS) that includes superoxide and hydrogen peroxide species has been associated with several disease states including cancer [6]. For example, prostate cancer is associated with aberrant changes in ROS and higher oxidative stress has been found in benign epithelium of prostate cancer patients as compared to men without the disease $[7,8]$. Increased hydrogen peroxide levels has been reported in exhaled breath condensate in patients with localized breast malignancy, which correlated with clinical severity [9]. Additionally, increased superoxide species were detected in breast and colon carcinoma [10]. With regards to ROS and EMT; Transforming Growth FactorBeta (TGF- $\beta$-mediated EMT involved increased hydrogen peroxide and Mitogen-activated protein kinase/Extracelluar signal reduced kinase (MAPK/ERK) signaling in proximal tubular epithelial cells [11], while Matrix Metalloproteinase-3 (MMP-3) mediated EMT in mammary epithelial cells involved increase in ROS and Snail [12]. Overexpression of Snail in ARCaP prostate cancer cells has been shown to induce EMT and ROS (hydrogen peroxide and superoxide), possibly by regulating oxidative stress-responsive genes [13]. Some of the transcription factors known to be involved in immediate early gene expression are also regulated by ROS.

Snail transcription factor, a zinc finger protein, can induce EMT which is associated with repression of Ecadherin and induction of vimentin expression and leads to increased cell invasion and migration [14]. Snail has been shown to be associated with increased tumor motility and invasion by induction of epithelial-mesenchymal transition (EMT) [15]. Snail represses E-cadherin transcription in vitro and in vivo by binding to 5'-CACCTG-3' sequence in the E-cadherin promoter [16]. Epithelial cells that ectopically express Snail adopt a fibroblastic phenotype and acquire tumorigenic and invasive properties [17].
Previous reports have shown that ARCaP and LNCaP prostate cancer cells stably transfected with Snail displayed decreased adhesion and increased cell migration [15]. It is also reported that Snail confers resistance to cell death [18], which provides a selective advantage for tumors that become malignant.

Signal transducers and activators of transcription (STAT) are proteins that regulate gene expression by affecting transcription. Activation of the Janus Kinase/Signal transducers and activators of transcription (JAK/STAT) pathway has also been observed in response to generation of intracellular ROS and exogenous hydrogen peroxide $\left(\mathrm{H}_{2} \mathrm{O}_{2}\right)$ STATs have been implicated in cell growth and survival during oncogenesis. STAT3 has been shown to regulate transcription factors such as twist and the Snail family that are able regulate E-cadherin expression during EMT. Using the ARCaP model, Zhau et al. [19] demonstrated a link between LIV-1, a downstream target of STAT3 and EMT. The authors concluded that signaling through STAT3Snail-LIV-1 resulted in an increased expression of receptor activator of nuclear factor $\mathrm{kB}(\mathrm{NF}-\mathrm{kB})$ ligand, which facilitates bone metastasis during prostate cancer progression Constitutive activation of STAT-3 has been observed in many human tumors including prostate [20]. The present study has gone further to elucidate specifically the origin and role of superoxide species in the EMT process and whether it can be antagonized by MSKE. We have previously established an ARCaP and LNCaP human prostate cancer EMT cell model by overexpression of Snail transcription factor $[21,22]$. Utilizing these models, we report here that Snail-mediated EMT is partly regulated by mitochondrial superoxide signaling in prostate cancer cells. Additionally, the antioxidants MSKE and SOD inhibit Snail-mediated superoxide, and reverts EMT. Finally, we show that MSKE may antagonize Snail-mediated signaling by inhibiting the JAK/STAT pathway.

\section{Methods}

\section{Reagents and antibodies}

RPMI 1640 medium (1X with L-glutamine and without L-glutamine and phenol red medium) and penicillinstreptomycin were from Mediatech (Manassas, VA). Protease inhibitor cocktail was from Roche Molecular Biochemicals, Indianapolis, IN. Mouse monoclonal antihuman E-cadherin antibody and rat tail collagen were from BD Transduction Laboratories, Lexington, KY. Mouse monoclonal anti-human vimentin antibody and mouse monoclonal anti-human Stat3 was from Santa Cruz Biotechnology, Santa Cruz, CA. Rabbit monoclonal anti-phospho-Stat3 were from EMD Millipore (Billerica, MA). Phorbol 12-myristate 13-acetate (PMA), and mouse monoclonal anti-human actin antibody were from SigmaAldrich, Inc., St Louis, MO. Geneticin (G418) and superoxide dismutase (SOD) were from EMD Corp BioScience 
(Brookfield, WI). MSKE was kindly provided by $\mathrm{Dr}$ Tamaro Hudson, Howard University, Washington, DC, and the preparation of the extract has been previously described [4]. Rat monoclonal anti-human Snail antibody and Horseradish perioxidase (HRP)-conjugated goat antirat antibody were from Cell Signaling Technology, Inc., Danvers, MA. HRP-conjugated sheep anti-mouse and the Enhanced chemiluminescence (ECL) detection reagent were purchased from Amersham Biosciences, Buckingham, England. Fetal bovine serum (FBS) and Charcoal/ dextran treated FBS (DCC-FBS) were from Hyclone, South Logan, UT. Dihydroethidium bromide (DHE) and Mitosox staining kit were obtained from Invitrogen, Carlsbad, CA. Hydro-Cy3 dye was kindly provided by Dr Niren Murthy, Georgia Institute of Technology, Atlanta, GA. The Snail cDNA construct was kindly provided by Dr Mien-Chie Hung, University of Texas, Houston, TX.

\section{Cell lines and culture}

LNCaP human prostate cancer cells were obtained from ATCC (Manassas, VA). LNCaP cells stably transfected with constitutively active Snail cDNA has been described previously [22]. Cells were grown in RPMI supplemented with $10 \%$ fetal bovine serum and $1 \mathrm{X}$ penicillin-streptomycin, at $37^{\circ} \mathrm{C}$ with $5 \% \mathrm{CO}_{2}$ in a humidified incubator.

\section{Transfection assay}

Stable transfection of Snail cDNA was performed in epithelial ARCaPE cells [23,24] utilizing Lipofectamine 2000 (Invitrogen) as previously described [21] to generate ARCaP-Neo, ARCaP-Snail low, and ARCaP-Snail high clones.

\section{Western blot analysis}

Western blot was performed as described previously [21]. The membranes were stripped using stripping buffer (Pierce Biotechnology, Inc., Rockford, IL) prior to reprobing with a different antibody. For treatments, 70\% confluent cells were serum-starved in phenol red-free serum-free RPMI containing penicillin/streptomycin for $24 \mathrm{~h}$ prior to treatment with MSKE or SOD in phenolfree serum-free RPMI containing 5\% FBS DCC-FBS for 3 days.

\section{In vitro measurement of superoxide with DHE}

For in vitro experiments, $70 \%$ confluent cells were washed with PBS followed by trypsin digestion. Cells were pelleted at $300 \mathrm{~g}$ for $2 \mathrm{~min}$, the supernatant removed and the cells resuspended in $500 \mu \mathrm{L}$ of HANKS with 5\% FBS. $10 \mu \mathrm{M}$ DHE (to detect superoxide) was added to cells, followed by incubation for $30 \mathrm{~min}$ while gently rocking in the dark. 20,000 cells were gated and analyzed by Fluorescence Activated Cell Sorting (FACS).

\section{In vitro measurement of superoxide with HydroCy3}

20,000 cells were plated in RPMI without antibiotics in a 6-well plate. The cells were then placed overnight in $37^{\circ} \mathrm{C}$ with $5 \% \mathrm{CO}_{2}$ in a humidified incubator. The next day cells were serum starved in RPMI without L-glutamine and phenol red for three hours followed by replacement of media with $90 \mu \mathrm{L}$ PBS/HEPES buffer plus $10 \mu \mathrm{L}$ of $25 \mu \mathrm{M}$ Hydro-Cy3 for $15 \mathrm{~min}$ at $37^{\circ} \mathrm{C}$, and subsequent imaging with a fluorescence microscope. To measure superoxide in cell lysate, $100 \mu \mathrm{l}$ whole cell lysates prepared from untreated or treated cells was mixed with $90 \mu \mathrm{L}$ HEPES/PBS buffer and $10 \mu \mathrm{L}$ of $25 \mu \mathrm{M}$ of HydroCy3 for $1 \mathrm{~h}$ followed by OD measurement at 530/590 nm. Protein concentration was assayed with BCA reagent in whole cell lysates to be used to normalize OD readings.

\section{Mitosox staining}

5,000 cells were plated overnight in RPMI supplemented with $10 \%$ fetal bovine serum and $1 \mathrm{X}$ penicillinstreptomycin in 16-well chamber slides. The MitoSOX staining was performed as per manufacturer protocol. Briefly, $1 \mathrm{~mL}$ of $5 \mu \mathrm{M}$ MitoSOX reagent was added to the cells, covered with foil and placed at $37^{\circ} \mathrm{C}$ with $5 \%$ $\mathrm{CO}_{2}$ in a humidified incubator for 10 minutes. The cells were then washed three times with warm HBS/ $\mathrm{CA} / \mathrm{Mg}$ buffer. Cells were counter-stained with DAPI to view the nucleus and images taken with a fluorescence microscope.

\section{In vitro cell migration assay}

We utilized Costar 24-well plates containing a polycarbonate filter insert with an $8-\mu$ pore size, coated with collagen I. Following treatment with MSKE, N-acetylcysteine (NAC), or SOD for 3 days as described above, cells were trypsinized and 50,000 cells were plated in the upper chamber of the insert containing $0.1 \%$ fetal bovine serum (FBS) while the lower chamber contained 10\% FBS. Five $h$ later (for $\mathrm{ARCaP}$ ) or $24 \mathrm{~h}$ later (for $\mathrm{LNCaP}$ ), cells that had migrated to the bottom of the insert were fixed, stained, and counted to obtain the relative migration.

\section{Statistical analysis}

Statistical analysis was performed using ANOVA and Turkey's Multiple Comparison Test as Post-Hoc test from Graph Pad Prizm3 software; *p $<0.05$ was considered significant. Multiple experiments were performed in replicates of 3 .

\section{Results}

Mitochondria is the Source of Superoxide Species in ARCaP Cells Transfected with Snail

Hydrogen peroxide ROS-Snail signaling has been implicated with breast cancer [12], while prostate cancer cells have been shown to spontaneously produce hydrogen 
peroxide [25]. We have previously shown that Snail upregulates superoxide species in ARCaP cells in vitro and in vivo [13]. We sought to confirm this and elucidate the source of superoxide species in ARCaP prostate cancer cells. We utilized ARCaPE cells transfected stably with Snail that displayed increased Snail expression as compared to Neo control cells (Figure 1A). We treated live ARCaP-Neo and -Snail cells with phorbol myristate12 13-acetate (PMA) to induce superoxide, and stained with Hydro-Cy3, a novel hydrocyanine (Hydro-Cy) dye, which can detect superoxide and hydroxyl radical and is supposed to be more stable than the DHE stain, and imaged the staining (red). We found that PMA induced superoxide, while less staining was observed when SOD antagonist was added (Figure 1B). More importantly, it appeared as if the ARCaP-Snail cells displayed higher staining for superoxide species as compared to ARCaPNeo (Figure 1B). These results were also confirmed by using dihydroethidium (DHE) staining which revealed elevated levels of superoxide in ARCaPE cells transfected with Snail (ARCaP-Snail low, -Snail high) in vitro as compared to the control (ARCaP-Neo) (Figure 1C). We

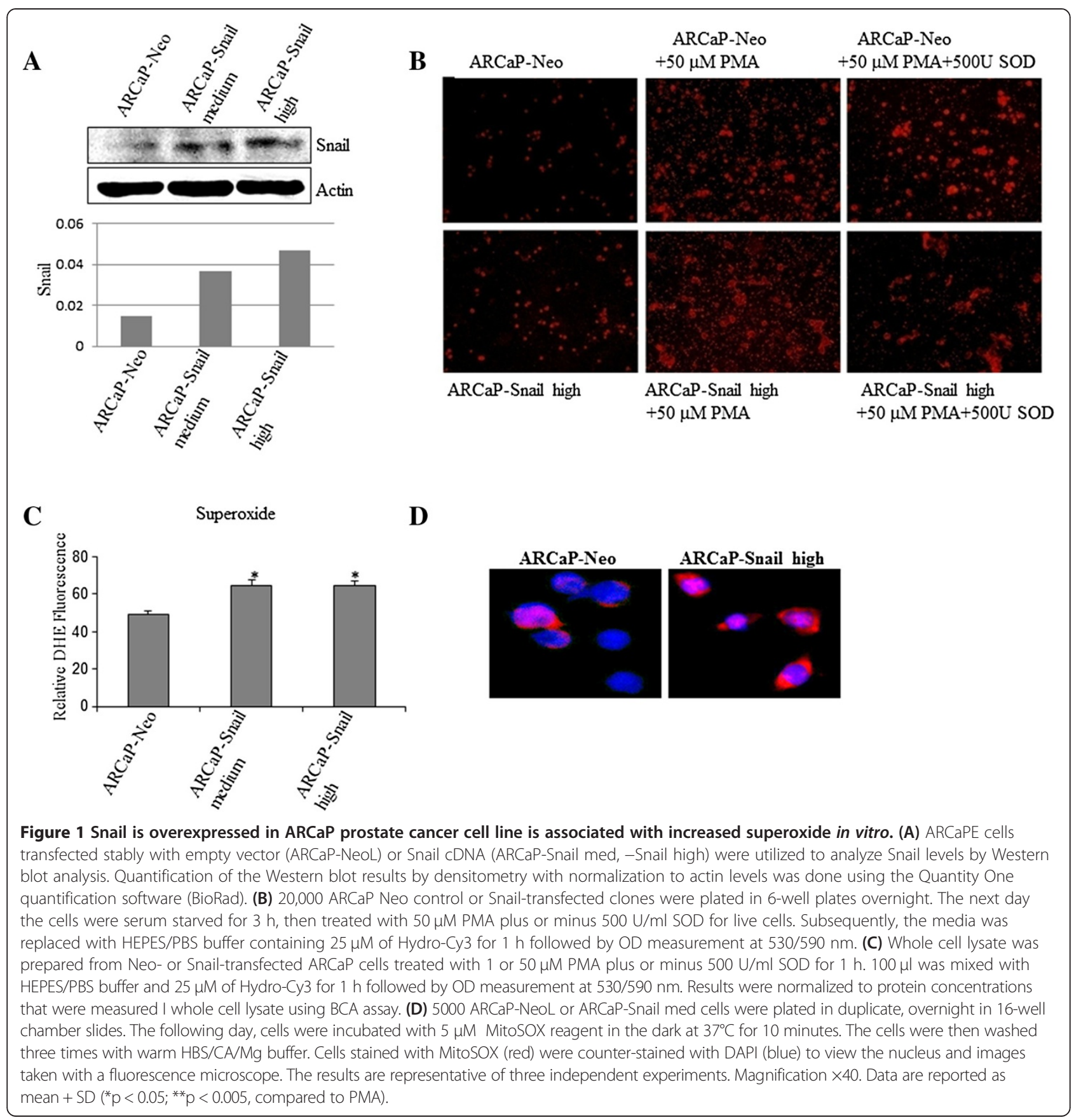


assayed for the source of increased superoxide species in response to Snail transfection by staining with Mitosox dye that detects mitochondrial superoxide. As shown in Figure 1D, there was a prominent increase in staining in the Snail-transfected ARCaP cells. Therefore, Snail is associated with increased levels of mitochondrial superoxide in vitro in ARCaP prostate cancer cells.

\section{Snail Increases Superoxide levels in LNCaP Cells}

Next we examined whether Snail can increase ROS in an androgen-dependent LNCaP prostate cancer cell line in order to compare the results obtained from Snail overexpression in androgen-independent ARCaP prostate cancer cells. We utilized LNCaP cells transfected with Snail that have previously been shown to undergo EMT [22]. We verified Snail expression by Western blot analysis in the Snail-transfected cells and showed that some clones expressed low (lo), medium (med) and high (hi) Snail expression (Figure 2A). We found that, in vitro, superoxide levels increased significantly in the Snail clones that expressed the most Snail (Figure 2B, C). The source of superoxide production in the LNCaP-Snail cells appeared to be mitochondrial in origin, as shown by mitosox staining (Figure 2D). Therefore, our results suggest that in the LNCaP cells, Snail can increase levels of mitochondrial superoxide.

MSKE and SOD antioxidants decrease superoxide levels in LNCaP and ARCaP cells transfected with snail, and is associated with decreased cell migration

MSKE, a plant product has recently been shown to promote apoptosis of prostate cancer cells, but not normal cells at $20 \mu \mathrm{g} / \mathrm{ml}$ [4]. For studies with MSKE, we decided to focus on the more aggressive ARCaP cells overexpressing Snail. We tested the effect of MSKE on cell viability in ARCaP Snail high cells. As shown in Figure 3A,

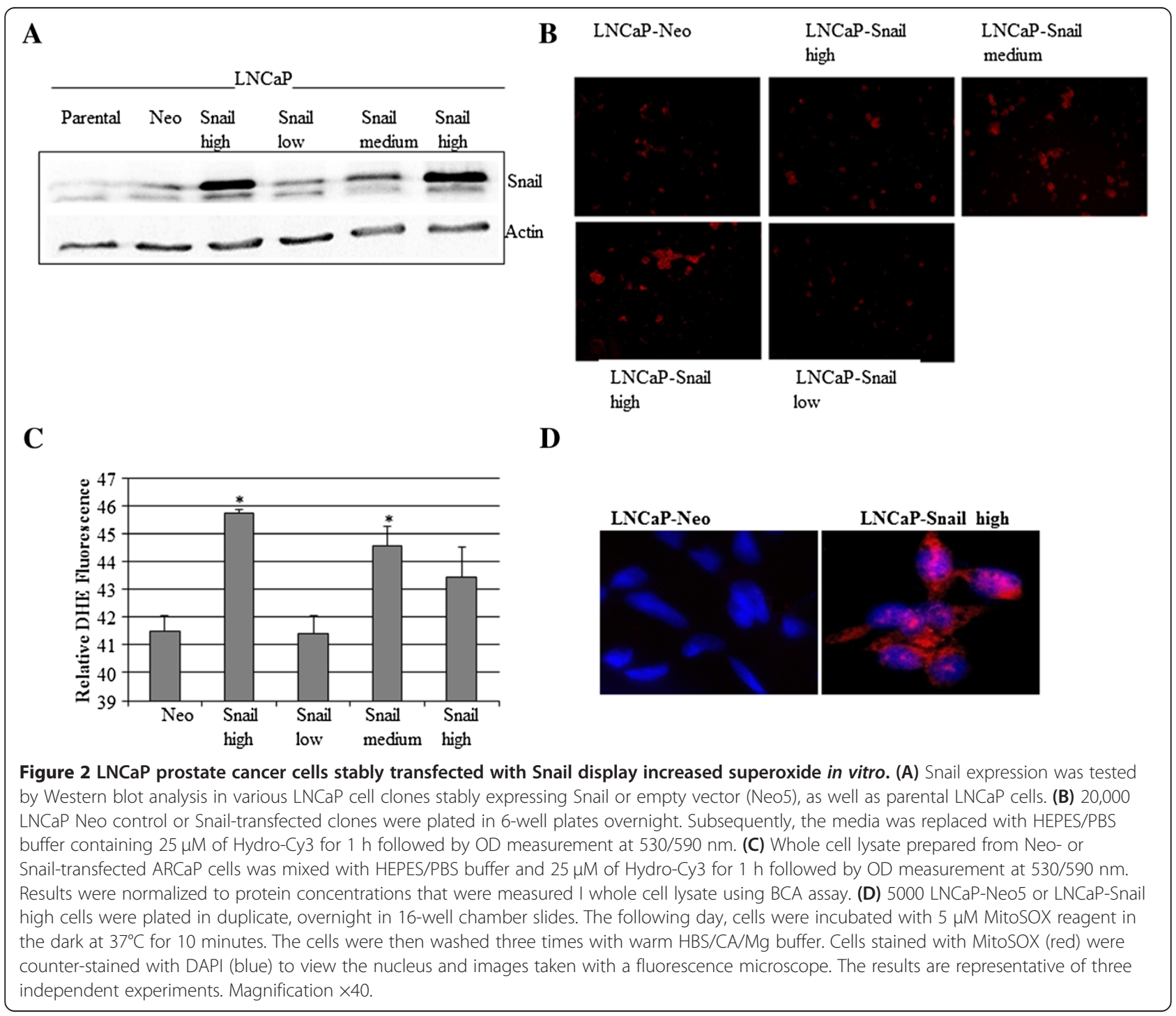




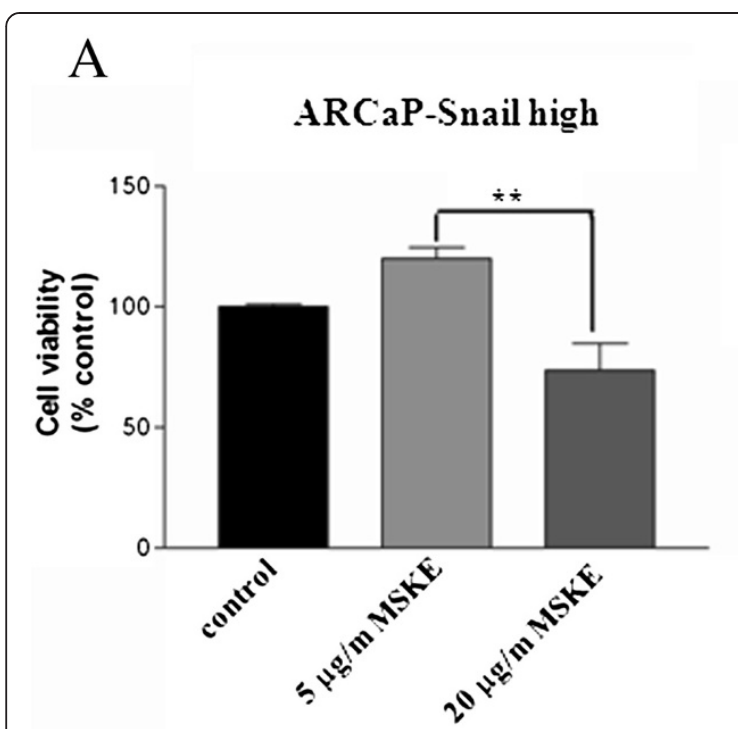

$\mathrm{C}$

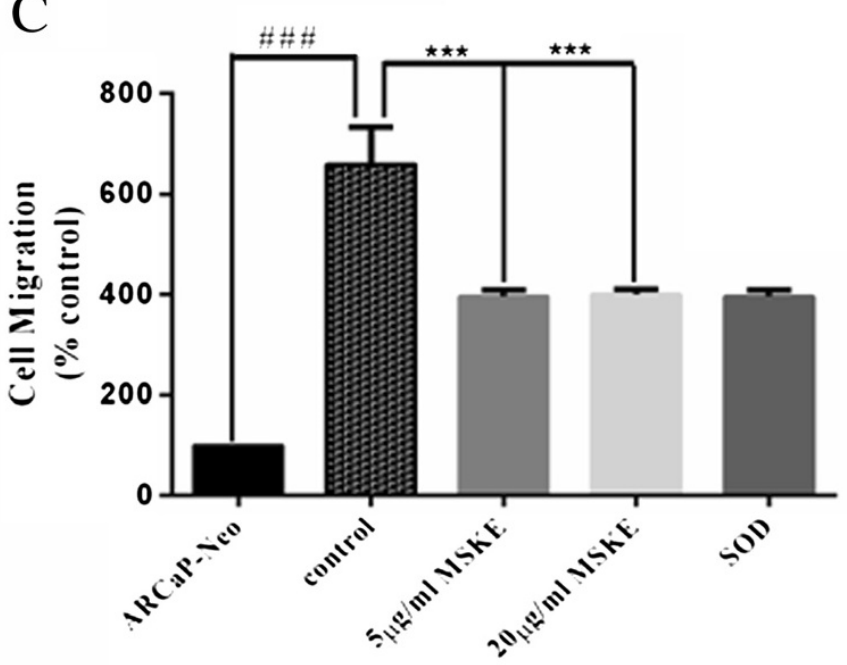

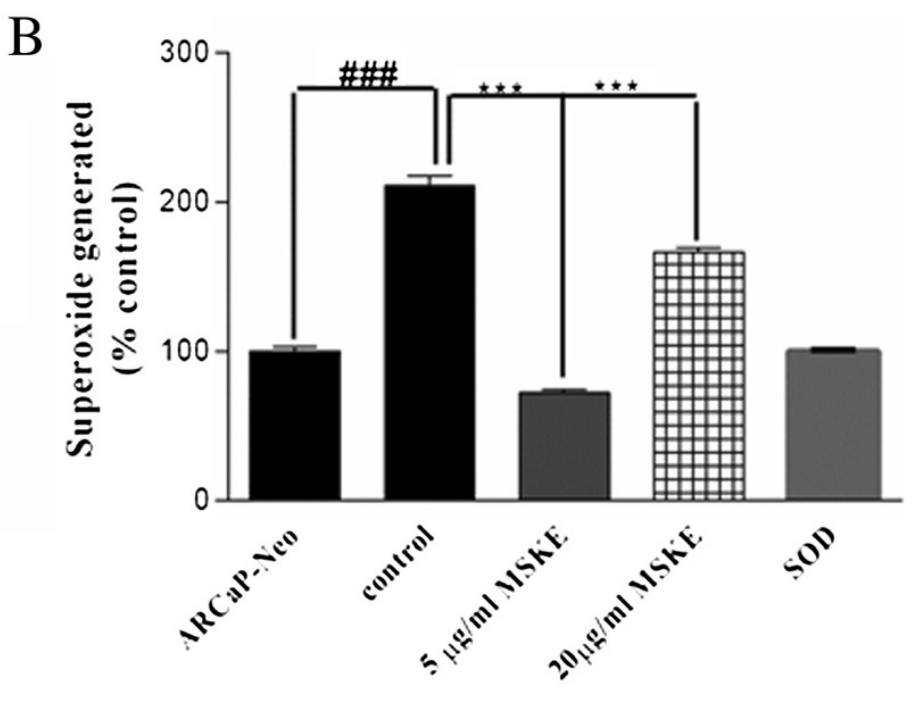

ARCaP-Snail high

\section{A RCaP-Snail high}

Figure 3 Muscadine grape extract (MSKE) and SOD abrogates Snail-mediated superoxide species in LNCaP and ARCaP cells and reduces cell migration. (A) LNCaP-Snail high, ARCaP-Snail med and ARCaP-Snail high cells were plated overnight, serum starved for $3 \mathrm{~h}$ followed by treatments with either $5 \mathrm{\mu g} / \mathrm{ml}$ MSKE, $20 \mathrm{\mu g} / \mathrm{ml} \mathrm{MSKE}$, or $500 \mathrm{u} / \mathrm{ml} \mathrm{SOD}$ for 3 days. Ethanol (EtOH) treated cells Neo- or Snail-transfected cells were utilized as controls. To assay for superoxide levels, whole cell lysates were prepared and $100 \mu$ incubated with $25 \mu \mathrm{M} \mathrm{Hydro-Cy3} \mathrm{for} 15$ min. OD was measured at 530/590 nm and normalized to protein concentrations. (B) LNCaP-Snail high or (C) ARCaP-Snail med was treated with $5 \mu \mathrm{g} /$ $\mathrm{ml} \mathrm{MSKE}, 20 \mathrm{\mu g} / \mathrm{ml}$ MSKE or $500 \mathrm{U} / \mathrm{ml} \mathrm{SOD}$ for 3 days. Cells were then trypsinized and 50,000 cells plated on collagen-coated boyden chambers overnight. For LNCaP cells, since their cell migratory potential is low, a serum gradient was applied with $0.1 \%$ serum in the top chamber and $10 \%$ serum in the bottom chamber. For ARCaP cells, the top and bottom chamber both contained $0.1 \%$ serum. Cells that had migrated to the underside of the cell insert were solubilized with Sorenson solution and OD assayed at $590 \mathrm{~nm}$ to obtain relative cell migration. Results are representative of triplicate experiments performed independently, with data reported as mean $\pm \mathrm{SD}\left({ }^{*} \mathrm{p}<0.05 ;{ }^{* *} \mathrm{p}<0.005\right.$, compared to EtOH control (-) Snail-transfected cells).

$5 \mu \mathrm{g} / \mathrm{ml}$ did not affect cell viability after 3 days, while $20 \mu \mathrm{g} / \mathrm{ml}$ MSKE led to a significant decrease in cell viability. We examined the effects of MSKE on superoxide levels in both LNCaP- and ARCaP-Snail transfected cells. Interestingly, we found that $5 \mu \mathrm{g} / \mathrm{ml}$ MSKE was more effective in decreasing superoxide levels when compared to $20 \mu \mathrm{g} / \mathrm{ml}$ MSKE, which was comparable to superoxide dismutase (SOD), a superoxide scavenger (Figure 3B). We further tested whether the MSKE could also affect cell migration. For this we utilized ARCaPSnail high cells and LNCaP-Snail high cells, which were treated with MSKE for 3 days followed by cell migration 
assay on collagen type 1 using boyden chambers. As shown in Figure 3C, Snail overexpression resulted in greater migratory potential, which could be abrogated by MSKE in ARCaP and LNCaP cells. Therefore, we show that MSKE can antagonize superoxide production which is biologically associated with decreased cell migration.

\section{MSKE can revert EMT}

Since Snail can induce EMT and increase superoxide levels, we examined whether there could be a possible link between superoxide species and EMT by using MSKE and SOD antioxidant that can inhibit superoxide. ARCaP-Snail med and -Snail high cells displayed EMT as shown by increased levels of Snail and vimentin, and decreased levels of E-cadherin, as compared to ARCaP-Neo (Figure 4A, B). Treatment of ARCaP-Snail med and-Snail high cells with $5 \mu \mathrm{g} / \mathrm{ml}$ MSKE was more effective at reverting EMT than $20 \mu \mathrm{g} / \mathrm{ml} \mathrm{MSKE}$, as shown by greater re-expression of E-

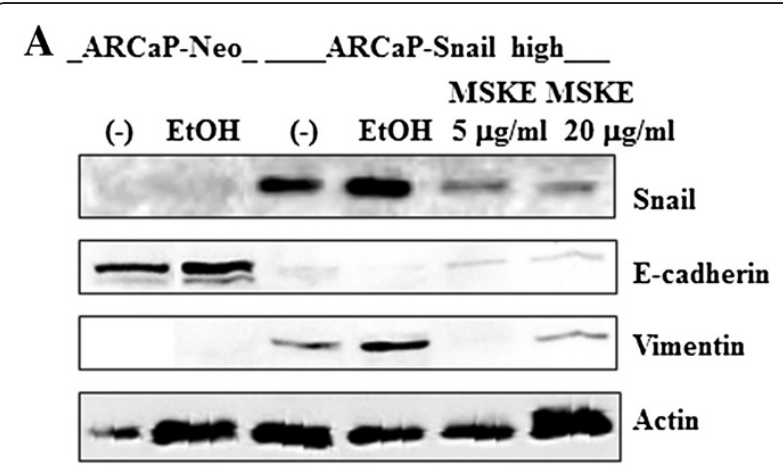

B

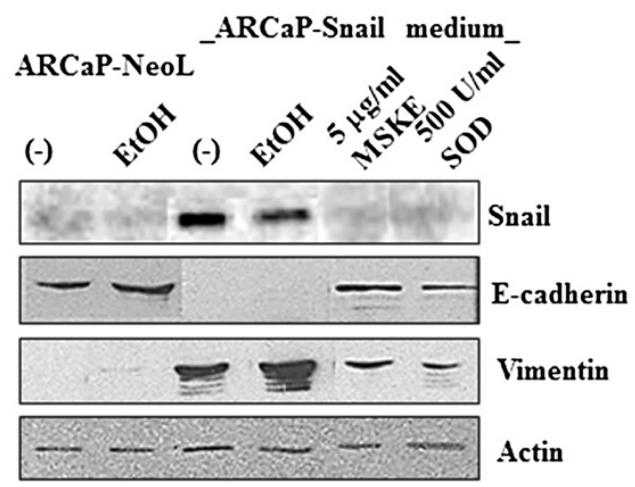

Figure 4 MSKE and SOD can revert Snail-mediated EMT in ARCaP cells. (A) ARCaP-Snail high cells were treated with 5 or $20 \mu \mathrm{g} / \mathrm{ml}$ MSKE for 3 days and Snail, E-cadherin and vimentin EMT markers analyzed by Western blot analyses. $5 \mu \mathrm{g} / \mathrm{ml}$ reverted EMT more efficiently than $20 \mu \mathrm{g} / \mathrm{ml}$ as observed by decreased vimentin and increased E-cadherin, as compared to untreated or EtOH-treated Snail high cells. (B) ARCaP-Snail med cells were treated with $5 \mu \mathrm{g} / \mathrm{ml}$ MSKE or $500 \mathrm{U} / \mathrm{ml} \mathrm{SOD}$ for 3 days followed by analysis of Snail, E-cadherin and vimentin by Western blot. Both MSKE and SOD reverted EMT as shown by increased E-cadherin and decreased vimentin. Untreated or EtOH treated cells were utilized as controls. Actin was used as a loading control. cadherin and decrease in vimentin protein in Western blot analyses when compared to untreated or control EtOH treated cells (Figure 4A, B). Similarly to treatment with $5 \mu \mathrm{g} / \mathrm{ml} \mathrm{MSKE}, 500 \mathrm{U} / \mathrm{ml}$ SOD could also revert EMT (Figure 4B). Both MSKE and SOD could inhibit Snail expression in both ARCaP-Snail clones. These results show for the first time that MSKE and SOD can revert the EMT process in ARCaP prostate cancer cells likely by suppressing Snail-mediated increase in ROS concentration.

\section{MSKE inhibits STAT-3 activity}

Since reactive oxygen species have been shown to activate the JAK/STAT pathway [26] and we have shown that MSKE can inhibit the expression of Snail-mediated superoxide, we wanted to examine the involvement of the JAK/STAT pathway.

ARCaP-Snail med and ARCaP Snail high cells were treated with $5 \mu \mathrm{g} / \mathrm{ml} \mathrm{MSKE}$ and $20 \mu \mathrm{g} / \mathrm{ml}$ for 3 days followed by analysis of STAT-3 levels and activity by western blot analysis. Interestingly, STAT-3 activity (pSTAT-3) was inhibited by $5 \mu \mathrm{g} / \mathrm{ml}$ MSKE while $20 \mu \mathrm{g} / \mathrm{ml}$ inhibited both STAT-3 levels and p-STAT-3 (Figure 5). Taken together, our data indicates that MSKE may exert its inhibitory effect in part by antagonizing the JAK/ STAT pathway in prostate cancer cells.

\section{Discussion}

This study evaluated the molecular mechanism(s) by which Snail transcription factor may contribute to cancer progression in prostate cancer through regulation of superoxide ROS and whether it can be antagonized by MSKE, a product with antioxidant properties. ROS are important mediators of tumor progression; increased hydrogen peroxide and superoxide species were found in colon carcinoma specimens, while high superoxide levels were present in breast cancer tissue specimens [10]. There has also been a report on increased hydrogen peroxide levels in human prostate tumors [27]. Since ROS is associated with tumor progression, and EMT is also linked to tumor progression [28], additional studies have shown that hydrogen peroxide can mediate EMT [11,29]. Previous studies have shown that Snail can increase hydrogen peroxide and superoxide levels in prostate cancer cells in vitro and in vivo [13]. However, the role of superoxide in prostate cancer is not well studied and its role in EMT has never been reported. We utilized prostate cancer cells overexpressing Snail, as an EMT model to study the role of superoxide in the EMT process.

Androgen-independent ARCaPE and androgen-depen dent LNCaP cells transfected with Snail have been previously shown to undergo EMT [21,22]. In our current study, we have shown that the levels of superoxide increased in both ARCaP and LNCaP cells transfected with Snail in vitro. Furthermore, the source of 


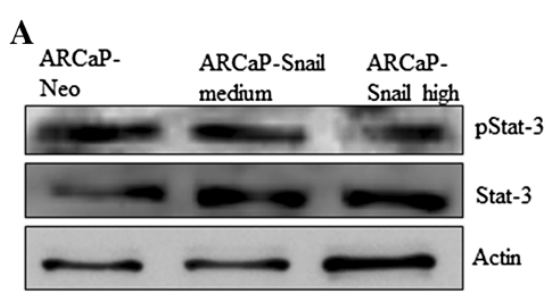

B

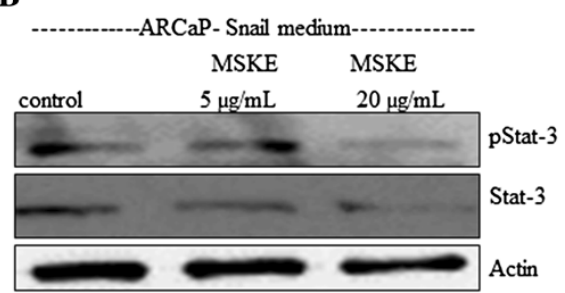

C

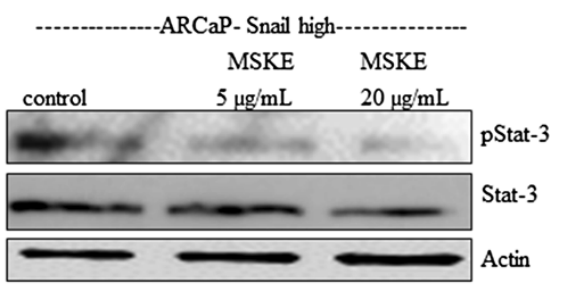

Figure 5 MSKE may exert its inhibitory effect on EMT and/or superoxide via antagonizing the JAK/STAT pathway in prostate cancer cells (A) STAT-3 and p-STAT-3 levels in ARCaP Neo and ARCaP-Snail med and ARCaP-Snail high (B) ARCaP-Snail med and (C) ARCaP Snail high cells were treated with $5 \mu \mathrm{g} / \mathrm{ml} \mathrm{MSKE}$ and $20 \mu \mathrm{g} / \mathrm{ml}$ for 3 days followed by analysis of STAT-3 and p-STAT-3 by western blot. Compared to untreated or DMSO control treated, $20 \mu \mathrm{g} / \mathrm{ml}$ showed a decrease in STAT-3 and p-STAT-3 as compared to $5 \mu \mathrm{g} / \mathrm{ml}$ MSKE or control. Untreated cells were utilized as controls. Actin was used as a loading control.

superoxide appears to be mitochondrial in origin, according to the Mitosox staining experiment. Previously, only hydrogen peroxide has been associated with EMT induction in cancer [11,12]. One study showed that transfection of MMP-3 gene into breast cancer cells could induce both hydrogen peroxide and Snail [12].

We tested MSKE, a plant product that has been shown to induce apoptosis and reduce cell proliferation in prostate cancer cells but not normal cells, by antagonizing ERK and PI3K signaling [4]. Muscadine grapes have unique aroma and flavor characteristics. Although a few studies reported high polyphenols content of muscadine grapes, little research has been conducted to evaluate the phenolic compounds bioactivities in any muscadine grape [30]. The major phytochemical constitute of MSKE is anthocyanin 3,5-diglucosides which is different from resveratrol [4]. The phenolic structure of anthocyanins is responsible for their antioxidant activity (ability to scavenge ROS) [5]. In our study $5 \mu \mathrm{g} / \mathrm{ml}$ MSKE led to a mesenchymal epithelial transition (MET) characterized by reexpression of E-cadherin and reduced vimentin levels. However, the higher dose $(20 \mu \mathrm{g} / \mathrm{ml})$ that has been shown to induce apoptosis in LNCaP cells [4] and decreased cell viability in ARCaP Snail high cells, was not as effective at inducing

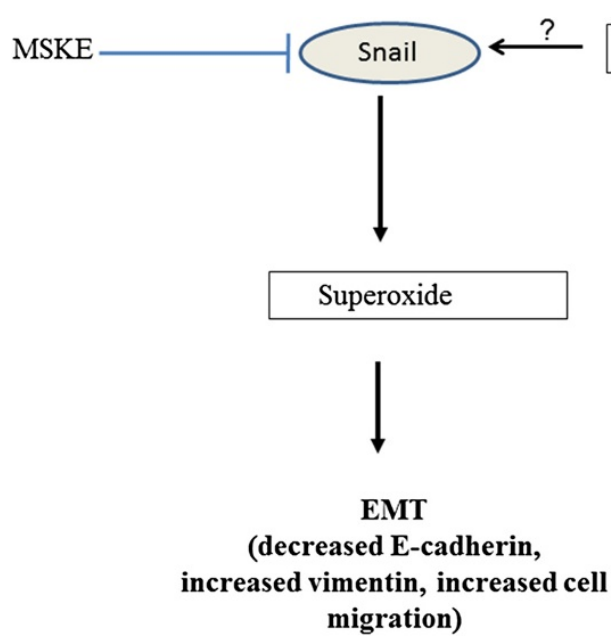

Figure 6 Pathway by which MSKE antagonizes Snail-mediated EMT in prostate cancer cells. Snail induces EMT via superoxide production which is characterized by decreased E-cadherin expression, increased vimentin expression and increased cell migration. MSKE antagonizes Snail-mediated EMT by inhibiting Snail expression possibly via inhibition of Stat-3 activity and superoxide production. 
MET and affected reexpression of E-cadherin, but not vimentin levels. Further support came from examination of superoxide levels showing that $5 \mu \mathrm{g} / \mathrm{ml}$ effectively inhibited superoxide levels in ARCaP-Snail cells by more than $50 \%$, while $20 \mu \mathrm{g} / \mathrm{ml}$ MSKE had minimal effect. This suggests lower doses of MSKE can be more effective at reverting EMT than higher doses, possibly by inhibiting superoxide. This is further supported by the data showing that the superoxide inhibitor, SOD, could significantly inhibit superoxide accompanied by a MET. This would be the first report of regulation of EMT by superoxide species. Interestingly, both doses of MSKE as well as SOD could inhibit Snail expression as well as cell migration. We do not currently understand why $20 \mu \mathrm{g} / \mathrm{ml}$ MSKE is just as effective as $5 \mu \mathrm{g} / \mathrm{ml}$ MSKE at reducing Snail levels and cell migration, yet it does not revert EMT or reduce superoxide levels as effectively. Studies have shown that it is possible that STAT-3 activation might be induced by ROS generation [26]. In our study we observed that while $5 \mu \mathrm{g} / \mathrm{ml}$ MSKE affected STAT-3 activity but not levels, $20 \mu \mathrm{g} / \mathrm{ml}$ MSKE did show an inhibition of STAT-3 levels and STAT-3 activity. There is obviously a difference in signaling between the low and high doses of MSKE and the high dose may act by inhibiting the JAK/STAT pathway leading to apoptosis while the lower dose may also inhibit STAT-3 activity and inhibit EMT. However, both doses inhibit Snail expression. Snail has not only been implicated in EMT but also in cell survival [31]. The difference between low and high dose of MSKE needs to be investigated further.

\section{Conclusions}

Collectively, our results indicate that Snail leads to increased levels of mitochondrial superoxide and EMT (Figure 6). Furthermore, MSKE and SOD reverts EMT by targeting Snail expression (Figure 6), underscoring the importance of targeting these pathways with various inhibitors and antioxidants. These studies show that superoxide species may play a role in the EMT process and that use of various antioxidants such as MSKE may be able to antagonize EMT and prostate cancer progression in future.

\footnotetext{
Abbreviations

MSKE: Muscadine grape skin extract; EMT: Epithelial mesenchymal transition; ROS: Reactive oxygen species; STAT-3: Signal transducer and activator of transcription 3.

\section{Competing interests}

The authors declare that they have no competing interest.

\section{Authors' contributions}

LB: performed experiments, analyzed data and generated figures and manuscript. PB: performed experiments, analyzed data and generated figures and manuscript. RSA: conducted DHE studies. KK: synthesized and provided the HydroCy3 dye. NM: synthesized and provided the HydroCy3 dye. VOM: designed project, project coordination, and manuscript preparation. All authors have read and approved the final version of the manuscript.
}

\section{Acknowledgements}

This project was supported by grants from the National Institutes of Health. NIH/NIMHD/RCMI Grant \#8 G12 MD007590 and NIH/NIMHD/P20 Grant \#2 P20 MD002285.

Grant supported by: NIH grants 1P20MD002285 (VOM), G12RR03062 (VOM).

\section{Author details}

${ }^{1}$ Center for Cancer Research and Therapeutic Development, Department of Biological Sciences, Clark Atlanta University, 223 James P Brawley Dr SW, 30314 Atlanta, GA, USA. ${ }^{2}$ Department of Pathology, Emory University School of Medicine, Washington, DC 20060, USA. ${ }^{3}$ Department of Medicine, Howard University, Washington, DC 20060, USA. ${ }^{4}$ Department of Biomedical Engineering, Georgia Institute of Technology, Atlanta, Georgia.

Received: 11 December 2013 Accepted: 28 February 2014 Published: 12 March 2014

\section{References}

1. Greenspan P, Bauer J, Stanley H, Pollock SH, Gangemi JD, Mayer EP, Ghaffar A, Hargrove JL, Hartle DK: Antiinflammatory properties of the muscadine grape (vitis rotundifolia). J Agric Food Chem 2005, 53(22):8481-8484.

2. He F, Mu L, Yan G, Liang N, Pan Q, Wang J, Reeves M, Duan C: Biosynthesis of anthocyanins and their regulation in colored grapes. Molecules 2010, 15:9057-9091.

3. Lee JHTS: Ellagic acid and ellagitannins affect on sedimentation in muscadine juice and wine. J Agric Food Chem 2002, 50:3971-3976.

4. Hudson TS, Hartle DK, Hursting SD, Nunez NP, Wang TT, Young HA, Arany P, Green JE: Inhibition of prostate cancer growth by muscadine grape skin extract and resveratrol through distinct mechanisms. Cancer Res 2007 67(17):8396-8405.

5. Wang SYJH: Scavenging capacity of berry crops on superoxide radicals, hydrogen peroxide, hydroxyl radicals, and singlet oxygen. J Agric Food Chem 2000, 48:5677-5684.

6. Liou GY, Storz P: Reactive oxygen species in cancer. Free Radic Res 2010, 44(5):479-496.

7. Khandrika L, Kumar B, Koul S, Maroni P, Koul HK: Oxidative stress in prostate cancer. Cancer Lett 2009, 282(2):125-136.

8. Fleshner NE, Klotz LH: Diet, androgens, oxidative stress and prostate cancer susceptibility. Cancer Metastasis Rev 1998, 17(4):325-330.

9. Stolarek RA, Potargowicz E, Seklewska E, Jakubik J, Lewandowski M, Jeziorski A, Nowak D: Increased $\mathrm{H} 2 \mathrm{O} 2$ level in exhaled breath condensate in primary breast cancer patients. J Cancer Res Clin Oncol 2010, 136(6):923-930.

10. Haklar G, Sayin-Ozveri E, Yuksel M, Aktan AO, Yalcin AS: Different kinds of reactive oxygen and nitrogen species were detected in colon and breast tumors. Cancer Lett 2001, 165(2):219-224.

11. Rhyu DY, Yang Y, Ha H, Lee GT, Song JS, Uh ST, Lee HB: Role of reactive oxygen species in TGF-beta1-induced mitogen-activated protein kinase activation and epithelial-mesenchymal transition in renal tubular epithelial cells. J Am Soc Nephrol 2005, 16(3):667-675.

12. Radisky DC, Levy DD, Littlepage LE, Liu H, Nelson CM, Fata JE, Leake D, Godden EL, Albertson DG, Nieto MA, Werb Z, Bissell MJ: Rac1b and reactive oxygen species mediate MMP-3-induced EMT and genomic instability. Nature 2005, 436(7047):123-127.

13. Barnett P, Arnold RS, Mezencev R, Chung LW, Zayzafoon M, Odero-Marah $V$ : Snail-mediated regulation of reactive oxygen species in ARCaP human prostate cancer cells. Biochem Biophys Res Commun 2011, 404(1):34-39.

14. Cano A, Perez-Moreno MA, Rodrigo I, Locascio A, Blanco MJ, del Barrio MG, Portillo F, Nieto MA: The transcription factor snail controls epithelialmesenchymal transitions by repressing E-cadherin expression. Nat Cell Biol 2000, 2(2):76-83.

15. Neal CL, McKeithen D, Odero-Marah VA: Snail negatively regulates cell adhesion to extracellular matrix and integrin expression via the MAPK pathway in prostate cancer cells. Cell Adh Migr 2011, 5(3):249-257.

16. Peiro S, Escriva M, Puig I, Barbera MJ, Dave N, Herranz N, Larriba MJ, Takkunen M, Franci C, Munoz A, Virtanen I, Baulida J, Garcia de Herreros A: Snail1transcriptional repressor binds to its own promoter and controls its expression. Nucleic Acids Res 2006, 34:2077-2084.

17. Smith BN, Odero-Marah VA: The role of snail in prostate cancer. Cell Adh Migr 2012, 6(5):433-41. 
18. Vega S, Morales AV, Ocana OH, Valdés F, Fabregat I, Nieto MA: Snail blocks the cell cycle and confes resistance to cell death. Genes Dev 2004, 18:1131-1143.

19. Zhau H, Odero-Marah VA, Lue H, Nomura T, Wang R, Chu G, Liu ZR, Zhou BP, Huang WC, Chung LW: Epithelial to mesenchymal transition (EMT) in human prostate cancer: lessons learned from ARCaP model. Clin Exp Metastasis 2008, 25:601-610.

20. Turkson J, Jove R: STAT proteins: novel molecular targets for cancer drug discovery. Oncogene 2000, 19:6613-6626.

21. Odero-Marah VA, Wang R, Chu G, Zayzafoon M, Xu J, Shi C, Marshall FF, Zhau HE, Chung LW: Receptor activator of NF-kappaB Ligand (RANKL) expression is associated with epithelial to mesenchymal transition in human prostate cancer cells. Cell Res 2008, 18(8):858-870.

22. McKeithen D, Graham T, Chung LW, Odero-Marah V: Snail transcription factor regulates neuroendocrine differentiation in LNCaP prostate cancer cells. Prostate 2010, 70(9):982-992.

23. Xu J, Wang R, Xie ZH, Odero-Marah V, Pathak S, Multani A, Chung LW, Zhau HE: Prostate cancer metastasis: role of the host microenvironment in promoting epithelial to mesenchymal transition and increased bone and adrenal gland metastasis. Prostate 2006, 66(15):1664-1673.

24. Zhau HY, Chang SM, Chen BQ, Wang Y, Zhang H, Kao C, Sang QA, Pathak SJ, Chung LW: Androgen-repressed phenotype in human prostate cancer. Proc Natl Acad Sci U S A 1996, 93(26):15152-15157.

25. Xia C, Meng Q, Liu LZ, Rojanasakul Y, Wang XR, Jiang BH: Reactive oxygen species regulate angiogenesis and tumor growth through vascular endothelial growth factor. Cancer Res 2007, 67(22):10823-10830.

26. Simon AR, Rai U, Fanburg BL, Cochran BH: Activation of the JAK-STAT pathway by reactive oxygen species. Am J Physiol 1998, 275:C1640-C1652

27. Lim SD, Sun C, Lambeth JD, Marshall F, Amin M, Chung L, Petros JA, Arnold RS: Increased Nox1 and hydrogen peroxide in prostate cancer. Prostate 2005, 62(2):200-207.

28. Boyer B, Valles AM, Edme N: Induction and regulation of epithelialmesenchymal transitions. Biochem Pharmacol 2000, 60(8):1091-1099.

29. Dong R, Lu JG, Wang Q, He XL, Chu YK, Ma QJ: Stabilization of Snail by HuR in the process of hydrogen peroxide induced cell migration. Biochem Biophys Res Commun 2007, 356(1):318-321.

30. Yi W, Fisher J, Akoh C: Study of anticancer activities of muscadine grape phenolics in vitro. J Agric Food Chem 2005, 53(22):8804-8812.

31. Fan F, Samuel S, Evans KW, Lu J, Xia L, Zhou Y, Sceusi E, Tozzi F, Ye XC, Mani $S A$, Ellis LM: Overexpression of Snail induces epithelial-mesenchymal transition and a cancer stem cell like phenotype in human colorectal cancer cells. Cancer Med 2013, 1(1):6-16.

doi:10.1186/1472-6882-14-97

Cite this article as: Burton et al:: Muscadine grape skin extract reverts snail-mediated epithelial mesenchymal transition via superoxide species in human prostate cancer cells. BMC Complementary and Alternative Medicine 2014 14:97.

\section{Submit your next manuscript to BioMed Central and take full advantage of:}

- Convenient online submission

- Thorough peer review

- No space constraints or color figure charges

- Immediate publication on acceptance

- Inclusion in PubMed, CAS, Scopus and Google Scholar

- Research which is freely available for redistribution 